\title{
Testosterone: An Insight into Its Clinical and Biochemical Assessments
}

\author{
Hina Usmani ${ }^{1}$, Ravi Kant ${ }^{2}$
}

\begin{abstract}
Testosterone levels are very important to be maintained in males, but the level reduces as age advances. If symptoms of severe or chronic low testosterone are present, hormone deficiency is amenable, it may be caused by an active disease or condition. In this review, we have tried to summarize how testosterone biosynthesis, regulation, as well as metabolism occurs in the human body. How it plays numerous roles: starting from intrauterine life to an advanced age, various factors such as age, weight, sleep, food habits, etc., affecting testosterone levels in the body are also discussed. These factors are very important in understanding the clinical implications of testosterone on the health of an individual. We also summarize various assays that are currently done for testosterone evaluation.
\end{abstract}

Keywords: Immunoassay, Mass spectrometry, Sexual dysfunction, Testosterone, Type 2 diabetes mellitus.

Indian Journal of Medical Biochemistry (2021): 10.5005/jp-journals-10054-0173

\section{INTRODUCTION}

In 1935, David and colleagues extracted hormone from testicular material which was known as "Testosterone" (Fig. 1). It is important in the development of reproductive organs (prostate and testes) in males. It also facilitates secondary sexual characters. ${ }^{1}$ Apart from this, it is associated with well-being, health, and the prevention of osteoporosis. ${ }^{2,3}$ Its deficiency in males leads to protean manifestations including sexual dysfunction, bone loss, and frailty. ${ }^{4}$

It is secreted mainly by testicles and by ovaries (to less extent). Normal males secrete $4-12$ mg of testosterone per day. Adult males have approximately 7-8 times higher levels of testosterone. ${ }^{5}$ This is probably due to the greater production of testosterone in males than in females. Adult females are sensitive to testosterone.

Testosterone is a hormone that is also used as an intervention to treat many conditions such as low levels of this hormone in males. ${ }^{6}$

Testosterone in males is necessary for maintaining and developing reproductive tissues like the prostate, testis, seminal vesicles, epididymis, as well as penis. Testosterone is important in maintaining muscle strength and hair growth. To maintain balanced levels of testosterone, the rate of production should be balanced with metabolism and utilization. ${ }^{7}$

Symptoms of testosterone deficiency in adult males include:

- Reduced body and facial hair

- Loss of muscle mass

- Low libido, impotence, small testicles, reduced sperm count, and infertility

- Increased breast size

- Hot flashes

- Irritability, poor concentration, and depression

- Loss of body hair

- Brittle bones and an increased risk of fracture.

In some males having testosterone deficiency in addition to symptoms/conditions related to low testosterone could be improved by testosterone replacement therapy. For example, a man with osteoporosis and low testosterone can increase bone strength and reduce his fracture risk with testosterone replacement therapy. ${ }^{8}$
${ }^{1}$ Department of Biochemistry, All India Institute of Medical Sciences, Rishikesh, Uttarakhand, India

${ }^{2}$ Department of Medicine, All India Institute of Medical Sciences, Rishikesh, Uttarakhand, India

Corresponding Author: Ravi Kant, Department of Medicine, All India Institute of Medical Sciences, Rishikesh, Uttarakhand, India, Phone: +91 8475000266, e-mail: ravi.endo@aiimsrishikesh.edu.in

How to cite this article: Usmani H, Kant R. Testosterone: An Insight into Its Clinical and Biochemical Assessments. Indian J Med Biochem 2021;25(1):24-30.

Source of support: Nil

Conflict of interest: None

Surprisingly, low-dose testosterone restores libido in females affected by hypotestosteronemia. Disease in the pituitary gland may lead to reduced testosterone production from adrenal glands. They may experience low libido, reduced bone strength, poor concentration, or depression. ${ }^{9}$

\section{Biosynthesis of Testosterone}

Leydig cells are the key source for the synthesis of testosterone. It is also secreted in trace amounts in the adrenal cortex as well as by seminiferous tubule (Sertoli cells). ${ }^{10}$

Testosterone's de novo biosynthesis occurs continuously as Leydig cells are incapable of storing androgens such as testosterone.

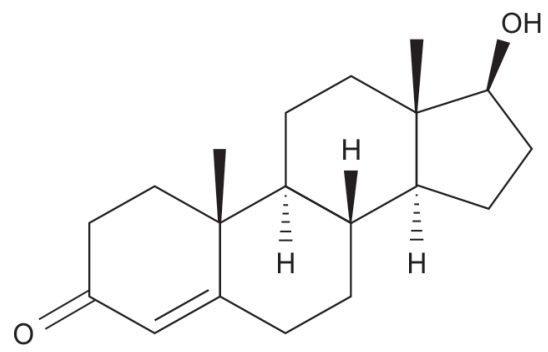

Fig. 1: Structure of testosterone molecule 


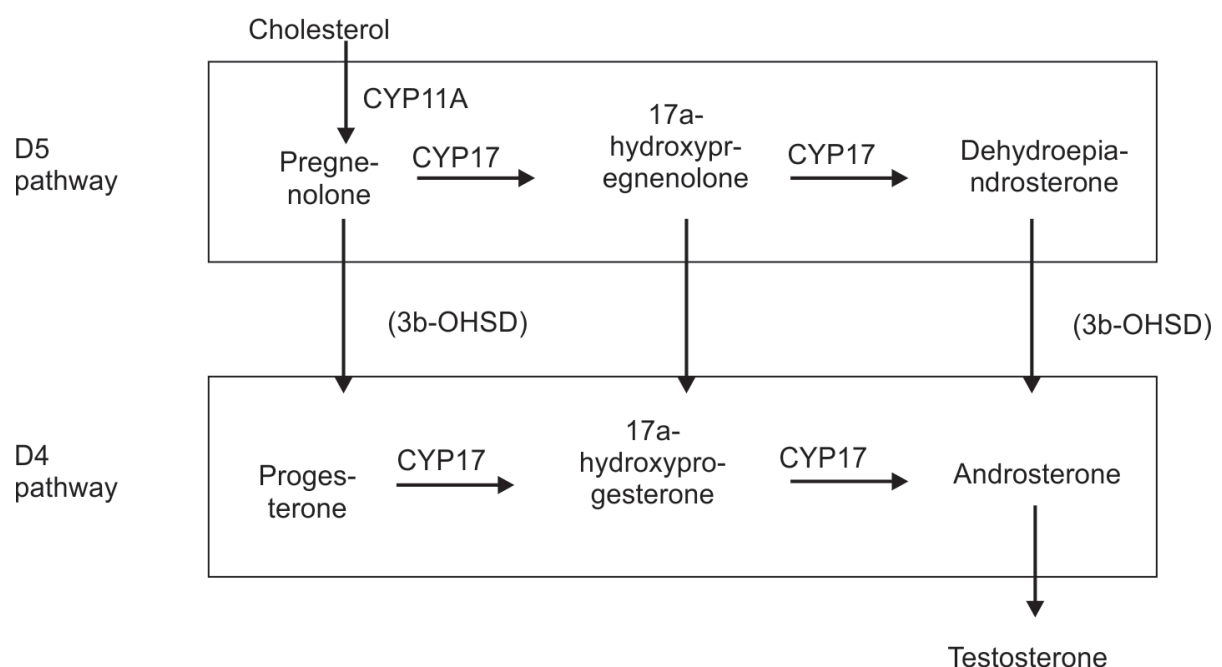

Fig. 2: Biosynthesis of testosterone

Testosterone

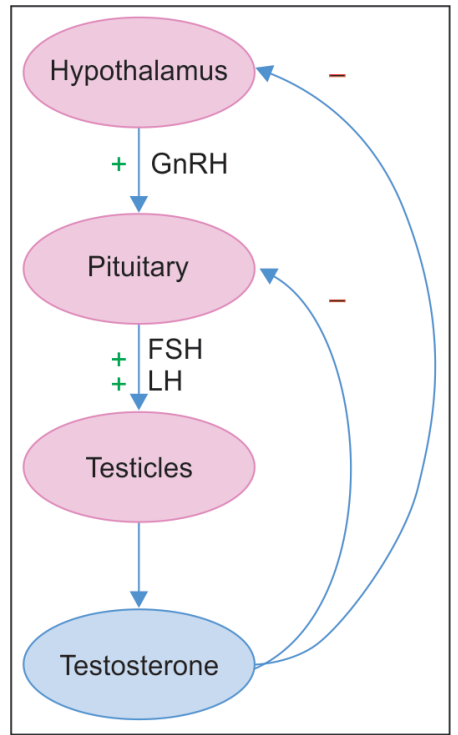

Fig. 3: Hypothalamus-pituitary-testicular axis

The synthesis of testosterone is initiated from a biomolecule known as cholesterol (Fig. 2). Cholesterol homeostasis in Leydig cell in vivo is maintained by luteinizing hormone (LH) which acts as a key regulatory factor. Cholesterol can be synthesized from acetyl-coenzyme $\mathrm{A}$. It can also be regulated by incorporation from low-density lipoproteins (LDLs) through receptor-mediated endocytosis. In addition, lipid homeostasis in Leydig cells is regulated by testosterone signaling. Storage of cholesterol is done as lipid droplets in the cytoplasm. The amount of testosterone synthesis is contrariwise to lipid droplets formed.

Testosterone biosynthesis occurs in differential enzymatic steps:

Step 1: Cholesterol is acted upon by hydroxylases leading to shortening of side-chain by cleaving the bond between C20 and C22 that ultimately leading to pregnenolone production.

After the formation of pregnenolone, the remaining steps take place in the endoplasmic reticulum (ER) via either the D4 or D5 pathway (D4 or D5 denotes double bond localization in steroid molecule). In humans, the D5 pathway is dominant than
D4. Conversion of pregnenolone to testosterone involves five enzymes for action.

- $3 \beta$-hydroxysteroid dehydrogenase (3ß-OHSD).

- $\Delta^{5-4}$ isomerase.

- 17a-hydroxylase.

- $\mathrm{C}_{1720}$ Lyase.

- $17 \beta$-hydroxysteroid dehydrogenase (17ß-OHSD).

Step 2: In the D4 pathway, progesterone which is an essential biomolecule is formed as a result of dehydration. This leads to the formation of an intermediate, i.e., 17a-hydroxyprogesterone. At this step, if removal of side-chain occurs then an intermediate androstene-3,17-dione is formed. Again reduction occurs at position C17, which is then converted into testosterone.

Step 3: In the D5 synthesis pathway, intermediates 17a-hydroxypregnenolone lead to the synthesis of testosterone via dehydroepiandrosterone (DHEA). ${ }^{11}$

\section{Regulation}

In males, testosterone is produced basically in Leydig cells. The quantity of Leydig cells is directed by LH and follicle-stimulating hormone (FSH). Additionally, a measure of testosterone delivered by existing Leydig cells is heavily influenced by $\mathrm{LH}$, which alters the functioning of $17 \beta$-hydroxysteroid dehydrogenase. ${ }^{10}$

Production of testosterone is under the control of the hypothalamo-pituitary testicular axis. ${ }^{12}$ When testosterone levels are low, gonadotropin-releasing hormone $(\mathrm{GnRH})$ is secreted by the hypothalamus stimulating the pituitary to release FSH and $\mathrm{LH}$. These hormones stimulate the testis to produce testosterone. A testosterone level via a negative feedback loop (from the hypothalamus and pituitary) leads to decreased production of $\mathrm{LH}$ and FSH (Fig. 3).

\section{Testosterone Levels vs Testosterone Action, Does Sex Hormone-binding Globulin (SHBG) Matter?}

Sex hormone-binding globulin is a glycoprotein principally produced in the liver. It binds to any of 17 sex hormones, including testosterone and estrogen, and transports these synthetic mixtures throughout the body. Testosterone is referred to as "bound" when attached to sex hormone-binding globulin (SHBG) and albumin. 
Free testosterone and the fraction bound to albumin are referred to as "bioavailable testosterone", and are biologically active. The total bound and free testosterone is referred to as total testosterone (Fig. 4).

Low SHBG is associated with high concentrations of triglycerides and LDL. ${ }^{13}$ Also, low degrees of SHBG are related to various cardiovascular diseases in both genders, including coronary disease, type 2 diabetes, and hypertension. ${ }^{14}$

High SHBG is hazardous particularly for males since it reduces the level of free testosterone. Significant levels of SHBG are related to sterility, a diminished sex drive, and erectile dysfunction (ED), particularly when testosterone levels are low. ${ }^{15}$ In both males and females, low degrees of free testosterone can lead to diminished muscle strength. It is found in disease states like hyperthyroidism and pregnancy and other estrogenic excess conditions.

\section{Variables Influencing Testosterone Levels}

- Age: Testosterone levels decrease with increasing age in men. ${ }^{16}$

- Exercise: Resistance training enhances testosterone levels. ${ }^{17,18}$ Endurance training in men may reduce testosterone levels. ${ }^{19}$

- Supplements: Deficiency of vitamin A leads to altered plasma testosterone levels. ${ }^{20}$ Secosteroid, vitamin D when taken as 400-1,000 IU/day (10-25 $\mathrm{gg} /$ day) elevates testosterone levels. ${ }^{21}$ Testosterone levels decrease in deficiency of zinc $(\mathrm{Zn}){ }^{22}$ However, there is no significant impact of zinc on serum testosterone on supplementation if one is already getting enough of the mineral from the diet. The study participants included men whose daily diets included the recommended amounts of zinc. Giving these men zinc supplements did not increase their testosterone levels. ${ }^{22}$

Moreover, $\mathrm{Zn}$ acts as a toxic repercussion against heavy metals and cigarette inflammatory agents. Zinc as a hormone balancer helps hormones such as sexual health, testosterone, and prostate functions. It acts as an antibacterial agent in men's urea system. It plays a role in epithelial integrity, showing that $Z n$ is essential for maintaining the lining of reproductive organs. It may have a regulative role in the progress of capacitation and acrosome reaction. In contrast, Zn deficiency impedes spermatogenesis and is a reason for sperm abnormalities, and has a negative effect on serum testosterone concentration.

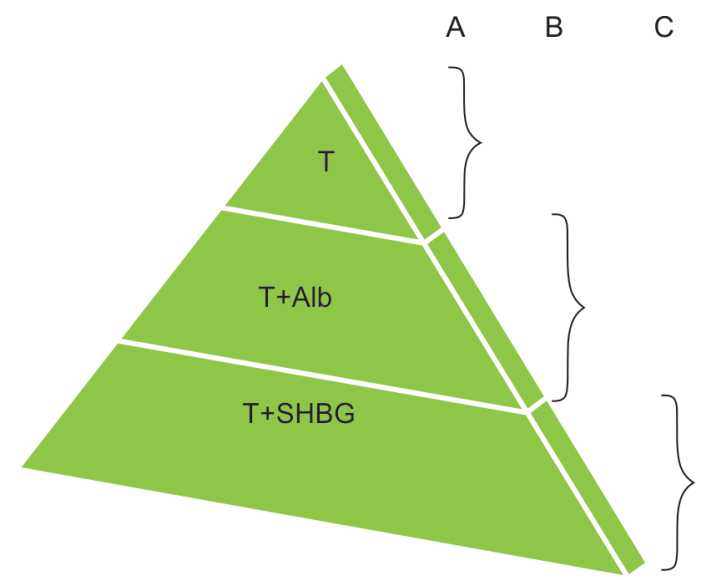

Fig. 4: Testosterone in circulation $\mathrm{T}=$ Testosterone. $\mathrm{A}=$ Free testosterone (1.5-2.0\%). B = Testosterone bound to albumin (33\%). C = Testosterone bound to sex hormone-binding globulin (65\%). Bioavailable testosterone is $A+B$, and total testosterone is $A+B+C$
- Weight reduction: Testosterone levels increase on reduction in weight. Fat cells aromatase converts testosterone into estradiol (female sex hormone). ${ }^{23}$ However, there is no relationship between body mass index and testosterone levels. ${ }^{24}$

\section{Other Factors}

- Sleep: Night-time testosterone levels increase during rapid eye movement (REM) sleep. ${ }^{25}$

- Behavior: Dominant nature in males can stimulate excessive testosterone release. ${ }^{26}$

- Drugs: Testosterone levels can be decreased by natural or manmade antiandrogens (e.g., spearmint tea). ${ }^{20,21}$

- Licorice: The formation of testosterone is reduced by licorice use. $^{27}$

\section{Distribution}

The plasma protein binding of testosterone is $98.0-98.5 \%$, with $1.5-2.0 \%$ free or unbound. ${ }^{28}$ It is bound $65 \%$ to SHBG and $33 \%$ bound weakly to albumin ${ }^{29-31}$ (Fig. 4).

\section{Metabolism of Testosterone}

Testis mainly secretes testosterone, and also secretes $5 a$-dihydrotestosterone ( $5 \mathrm{a}-\mathrm{DHT})$, androstenedione, androsterone, 17-hydroxyprogesterone, pregnenolone, and progesterone (Fig. 5). Testosterone transforms to dihydrotestosterone in the prostate. ${ }^{10}$

$5 a$-dihydrotestosterone produced by testosterone through $5 a$-reductase, is more potent than testosterone (3-5 times). The half-life of testosterone is approximately 12 minutes. ${ }^{15}$

Testosterone is converted to a-DHT in ER by an enzyme $5 a$-reductase, i.e., located in microsome. Testosterone and a-DHT binds to the same intracellular androgen receptor to regulate gene expression in target tissues producing different biological effects. $5 a$-reductase has two isoforms in humans. 5a-reductase type 1 and type 2 genes are located on chromosomes 5 and 2, respectively. They encode a protein of 259 and 254 amino acids, respectively. Instead of similarity, both isoforms show dissimilar biochemical properties. Working optimal $\mathrm{pH}$ for type 1 reductase is alkaline, while for type 2 reductase it is acidic. The tissue distribution of both isoforms is also different. Type 1, 5a-reductase is localized in non-genital organs like skin, liver, brain, prostate, testis, and ovaries while 5a-reductase type 2 is found in genital skin, epididymis, testis, prostate, and seminal vesicle, it is also found in breast, uterus, as well as the placenta.

5a-dihydrotestosterone is very important in cell growth and differentiation and also for normal sexual development as well as

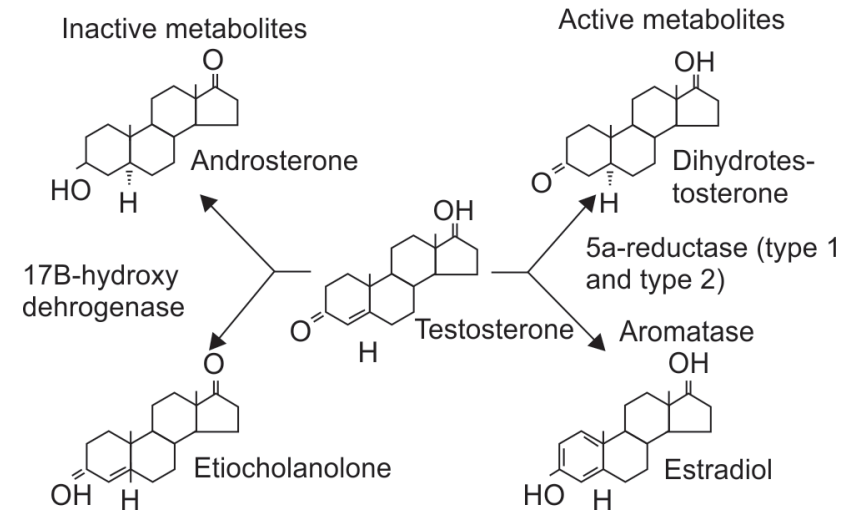

Fig. 5: Metabolism of testosterone 
virilization in men. It is mainly responsible for the deepening of the voice and the development of muscle mass. Largely, testosterone has effects due to its metabolites, i.e., estradiol and 5a-DHT (Table 1).

Partial androgen insensitivity syndrome (PAIS) or complete androgen insensitivity syndrome (CAIS) results due to altered properties of 5a-reductase type 2 as a result of mutation. Type 3a-HSD (hydroxysteroid dehydrogenase) eliminates dihydrotestosterone to form $3 a$-androstanediol by reducing 5a-DHT. Only Aldo-keto reductase family 1 member C2 (AKR1C2) activity can convert back $3 a$-androstanediol to $5 a-D H T$, for prostate growth. ${ }^{16}$ Varying reductase activity on different ketosteroid positions, mainly converts $5 a-D H T$ to $3 a$-diol (inactive) and is mainly excreted in the urine. Certain metabolites are excreted in their free form while others are glucuronidated in the liver before excreting out. The glucuronidation of a-DHT metabolite is correlated with numerous metabolic risk factors such as disturbed lipid profile, total fat mass, intrahepatic fat, diabetes mellitus, and insulin resistance. ${ }^{17,32}$

\section{Biological Effects of Testosterone}

Testosterone plays numerous roles starting from intrauterine life to advanced age (Table 2).

- Intrauterine life: A fetus having $46 \mathrm{XY}$ chromosomes is fated to develop into a male as chromosome $Y$ has a testicular determining gene that transforms undifferentiated gonad to testes. The testes consequently produce testosterone for development as well as the growth of the Wolffian system that includes vas deferens, seminal vesicle. DHT too is the main androgen causing external genitalia androgenization. ${ }^{33}$

- Puberty: Hypothalamus activation leads to increased release of GnRH to release LH and FSH. Stimulation of these hormones elevates the production of testosterone in testes to initiate secondary sexual characteristics related to puberty like spermatogenesis, libido, growth spurt, acne, erectile function, growth of body hair, and muscle mass, deepening of the voice.

- Bones: There are a few main effects of testosterone on bones.

- Via alteration by the aromatase enzyme, testosterone works opposite to osteoclastic activity. Therefore, enhancing bone resorption. ${ }^{34}$

- Via alteration by the 5a-reductase enzyme to DHT. It stimulates osteoblastic activity and hence, accelerates bone formation.

- Males having the hypogonadal condition are at risk of developing osteoporosis or osteopenia. This ultimately results in a fracture. ${ }^{18}$

- Libido: Testosterone is associated with increased libido.

- Erythropoiesis and anemia: Hematopoiesis is stimulated by testosterone through increased production of erythropoietin.

- Low testosterone levels and cardiovascular risk: Testosterone levels decrease gradually with age in males. Many observational and epidemiological studies have revealed, decreased levels of testosterone are related to enhanced risk of cardiovascular disease.

- Obesity, diabetes mellitus, metabolic syndrome: Metabolic syndrome has been termed as central adiposity (waist circumference is $>94 \mathrm{~cm}$ ) with hypertension, decreased HDL cholesterol and increased triglycerides, insulin resistance, and diabetes mellitus.

Testosterone is converted to estradiol in adipose tissue that contains high concentrations of aromatase. Reduced testosterone levels are associated with diabetes mellitus.

A study was done to evaluate the effect of testosterone therapy on glycemic control and insulin resistance in males having decreased levels of testosterone in addition to diabetes mellitus type 2. It was concluded that males who were undergoing testosterone therapy had reduced fasting blood sugar, glycated hemoglobin, insulin resistance, waist/hip ratio, waist circumference, and total cholesterol.

- Testosterone and aging:

Testosterone levels decrease as age increases. This drop-in availability of testosterone may start early but in the 50 s and $60 \mathrm{~s}$, it becomes clinically obvious. Reduction in testosterone levels affects both physiological functions (muscle mass, bone metabolism, cognitive function, erectile function, and libido) and pathophysiological functions such as obesity, insulin resistance, diabetes mellitus, metabolic syndrome, autoimmune disease, etc.

Sufficient availability of testosterone is cardioprotective. Obesity, diabetes, and metabolic syndrome are risk factors for coronary heart diseases also related to decreased levels of testosterone. It has been proposed that with reducing levels of testosterone in aging males, fat mass, as well as lean body mass, decreases. ${ }^{35}$

\section{Forms of Testosterone Supplements}

Various forms of testosterone replacement therapy are important in improving testosterone levels. ${ }^{36}$

\section{Skin Patch (i.e., Transdermal)}

Androderm, skin patch worn on the arm or upper body which is applied once a day.

\section{Gels}

Testim and AndroGel come in a pack of testosterone gel. Testosterone is directly absorbed via the skin when applied gel once a day. AndroGel, Axiron, and Fortesta also come in a pump. Natesto is a gel that is applied inside the nose.

\section{Mouth Patch}

Striant is a tablet that sticks to the upper gums above the incisor, the tooth just to the right or left of two front teeth. It is applied twice a day; it continuously releases testosterone into blood through oral tissues.

Table 1: Percentage of plasma protein binding of testosterone

\begin{tabular}{lllcccc}
\hline \multicolumn{7}{c}{ Plasma protein binding of testosterone } \\
\hline Compound & Group & Level $(n M)$ & Free (\%) & SHBG (\%) & CBG (\%) & Albumin (\%) \\
\hline Testosterone & Adult men & 23.0 & 2.23 & 44.3 & 3.56 & 49.9 \\
& Adult women & & & & & \\
& Follicular phase & 1.3 & 1.36 & 66.0 & 2.26 & 30.4 \\
& Luteal phase & 1.3 & 1.37 & 65.7 & 2.20 & 30.7 \\
& Pregnancy & 4.7 & 0.23 & 95.4 & 0.82 & 3.6 \\
\hline
\end{tabular}


Table 2: Biological effects of testosterone

\begin{tabular}{|c|c|c|c|}
\hline S. no. & Effect & Mechanism & Outcome \\
\hline 1 & Endocrine system & Hypothalamus regulates the production of testosterone & It has a negative feedback regulation \\
\hline 2 & Reproductive system & Testosterone is required for spermatogenesis & Low levels of it result in infertility in males \\
\hline 3 & Sexuality & Growth of testicles, penis, and pubic hair & $\begin{array}{l}\text { Decreased levels of testosterone result in the } \\
\text { development of female characters in males }\end{array}$ \\
\hline 4 & Central nervous system & Develops aggression and dominance & Decreased levels affect behavioral traits in males \\
\hline 5 & Skin and hair & $\begin{array}{l}\text { Growth of hair on the face, in armpits, and around } \\
\text { genitals }\end{array}$ & $\begin{array}{l}\text { Low levels result in alteration of male pattern of } \\
\text { hair distribution }\end{array}$ \\
\hline 6 & Muscle, fat, bone & Development of muscle bulk and strength & Decreases muscular strength \\
\hline 7 & Circulatory system & $\begin{array}{l}\text { Spurs bone marrow to produce red blood cells affect } \\
\text { cholesterol, blood pressure, and clot-busting ability }\end{array}$ & $\begin{array}{l}\text { Low levels of testosterone decrease } \\
\text { hematopoiesis }\end{array}$ \\
\hline 8 & Cardiovascular system & $\begin{array}{l}\text { Testosterone acts via binding to androgen receptor } \\
\text { altering myocardial and vascular cell behavior }\end{array}$ & $\begin{array}{l}\text { Low levels of testosterone are associated with } \\
\text { an increased risk of CAD }\end{array}$ \\
\hline 9 & Blood pressure & Testosterone acts on mean atrial pressure & $\begin{array}{l}\text { With an increased level of testosterone, blood } \\
\text { pressure increases }\end{array}$ \\
\hline 10 & $\begin{array}{l}\text { Diabetes mellitus, obesity, } \\
\text { and metabolic syndrome }\end{array}$ & $\begin{array}{l}\text { Testosterone acts via regulating insulin resistance and } \\
\text { glycemic control }\end{array}$ & $\begin{array}{l}\text { Low levels of testosterone result in metabolic } \\
\text { syndrome }\end{array}$ \\
\hline 11 & Aging & The level of testosterone decreases with increasing age & Results in loss of physiological functions \\
\hline
\end{tabular}

\section{Injections and Implants}

Testosterone can also be injected directly into muscles, or implanted as pellets in soft tissues. The body slowly absorbs the testosterone into the bloodstream.

Why not a simple testosterone pill?

Oral testosterone is available. However, their pharmacodynamics is unreliable and there are peaks and troughs in 24 hours duration, they are associated with hepatotoxicity. Using other methods, like gels, skin patches, injections, or orally disintegrating tablets, bypasses the liver and gets testosterone directly into the blood.

\section{Pros and Cons of Testosterone Treatment Modalities}

Worldwide, intramuscular injections are generally used formulations of testosterone which is not only the oldest one but also the most time-tested formulation. "For injections, the advantages include predictable on-treatment levels of testosterone. If a patient uses weekly injections, that will result in physiologic levels of testosterone. But, to avoid the weekly needle stick, patients and clinicians usually opt for a higher dose, which is given twice a month".

The cons, however, is that this less frequent dosing results in peaks and troughs in serum testosterone concentrations. The weekly smaller dose, despite the inconvenience, yields more even levels. "It is also inexpensive, for many patients who do not have insurance or have limited coverage, injections are one formulation that they can afford". ${ }^{36}$

\section{Who should be Screened for Testosterone Deficiency?}

Screen for TD in:

- Adult men with consistent and multiple signs of TD.

- All men presenting with ED, loss of spontaneous erections, or low sexual desire.

- All men with type 2 diabetes mellitus, $\mathrm{BMI}>30 \mathrm{~kg} / \mathrm{m}^{2}$ or waist circumference $>102 \mathrm{~cm}$.

- All men are on long-term opiate, antipsychotic, or anticonvulsant medication.

TD = Testosterone deficiency; ED = Erectile dysfunction; $\mathrm{BMI}=$ Body mass index

\section{Assays for Testosterone Measurement ${ }^{37}$}

Diagnosing testosterone deficiency is quite challenging. Variations in serum testosterone levels may be due to seasonal or age-related reasons. Some medications such as opiates and glucocorticoids in addition to disease can temporarily alter testosterone concentration. Change in level of total testosterone is due to altered SHBG. This ultimately affects age and results in medical comorbidities. Different assays are available for measuring testosterone levels as well as performance characteristics (Table 3 ).

\section{Immunoassays}

In the clinical laboratory, immunoassays are commonly used to measure total testosterone levels. Currently, there are two widely used assays for it. These include radioimmunoassay (RIA) and chemiluminescent immunoassays. Both of these assays can be done on plasma or serum. This is done after extraction or chromatography. These additional steps are more laborious, can remove cross-reacting hormones as well as interfering proteins.

RIAs: It measures testosterone level when serum is incubated with anti-testosterone antibodies linked to a radioactive antigen. Total testosterone concentration can be measured when antigen present in serum detaches radioactive antigen from its antigen-binding site, releasing particles.

Chemiluminescent assays: This assay uses an antibody that is linked to an enzyme, usually horseradish peroxidase (HRP). Serum testosterone is incubated in a well coated with antibodies specific to this hormone. After complex formation, a secondary antibody is added followed by adding a chemiluminescent substrate. This produces a detectable luminescent signal. ${ }^{37}$

Benefits of immunoassays: Precisely rapid, simple, and comparatively affordable, cost-effective with high output.

Drawbacks of immunoassays: Concentrations of testosterone were overestimated, susceptible to matrix effects, limited accuracy for testosterone levels (not $>300 \mathrm{ng} / \mathrm{dL}$ ) when performed.

Radioimmunoassay also has a drawback as this immunoassay creates radioactive waste. Essentially, due to the use of antibodies 
Table 3: Assays for testosterone measurement

\begin{tabular}{|c|c|c|c|}
\hline Method of assay & $\begin{array}{l}\text { Minimum level } \\
\text { measured }\end{array}$ & Advantages & Disadvantages \\
\hline Radioimmunoassay & $300 \mathrm{ng} / \mathrm{dL}$ & $\begin{array}{l}\text { Precisely rapid, simple, and comparatively } \\
\text { affordable, cost-effective with high throughput }\end{array}$ & Create radioactive waste \\
\hline $\begin{array}{l}\text { Chemiluminescent } \\
\text { assays }\end{array}$ & $300 \mathrm{ng} / \mathrm{dL}$ & $\begin{array}{l}\text { Precisely rapid, simple, and comparatively } \\
\text { affordable, cost-effective with high throughput }\end{array}$ & $\begin{array}{l}\text { Concentrations of testosterone are } \\
\text { overestimated, susceptible to matrix effects, } \\
\text { limited accuracy }\end{array}$ \\
\hline Mass spectrometry & $144 \mathrm{ng} / \mathrm{dL}$ & $\begin{array}{l}\text { In a single run, able to detect many analytes, } \\
\text { accuracy over a wide range of concentrations, } \\
\text { specificity to detect compounds, and the error rate } \\
\text { is very low antibody cross-reactivity reactions }\end{array}$ & $\begin{array}{l}\text { Require high technical expertise, operating cost } \\
\text { is high, lacking standardization, special disposal } \\
\text { is required for solvents used }\end{array}$ \\
\hline
\end{tabular}

Table 4: Comparison between gas and liquid chromatography

\begin{tabular}{|c|c|c|}
\hline S. no. & Gas chromatography & Liquid chromatography \\
\hline 1 & Requires large sample volume & $\begin{array}{l}\text { Requires low sample } \\
\text { volume }\end{array}$ \\
\hline 2 & $\begin{array}{l}\text { Provides a more } \\
\text { comprehensive screen of an } \\
\text { individual's steroid profile }\end{array}$ & Open to automation \\
\hline 3 & $\begin{array}{l}\text { Does require chemical steroid } \\
\text { derivatization }\end{array}$ & $\begin{array}{l}\text { Does not require chemical } \\
\text { steroid derivatization }\end{array}$ \\
\hline 4 & More time-consuming & Less time-consuming \\
\hline 5 & $\begin{array}{l}\text { Suitable for athlete/ } \\
\text { bodybuilder using anabolic } \\
\text { androgenic steroid }\end{array}$ & $\begin{array}{l}\text { Can be used for any } \\
\text { patient's sample }\end{array}$ \\
\hline
\end{tabular}

targeting specific chemical moieties on steroid molecules and high specificity for testosterone or DHT, immunoassays do not detect anabolic steroids that do not have this type of structure. As a result, immunoassay will show low levels of circulating testosterone in an anabolic steroid user, despite looking highly masculinized. ${ }^{38}$

\section{Mass Spectrometry (MS)}

As immunoassays have limitations such as in specificity and precision mainly at low to very low levels of testosterone. Mass spectrometry when used in combination with chromatography has gradually been translated from a laboratory research technique to clinical application. This is mainly due to its ability to identify many analytes, its high-performance accuracy over a wide variety of concentrations. It is specific to detect compounds of interest and is immune to antibody cross-reactivity reactions. It involves preparation of sample to remove interfering matrix (such as salts and proteins), chromatographic separation, ionization of analyte, and analysis with a spectrometer.

Chromatographic separation can be performed in a gas (GC) or a liquid (LC). Some of the characteristics of GC and LC are discussed below (Table 4):

Mass spectrometry has increased the specificity and accuracy of performance of tandem (MS/MS) by applying the second round of ionization. These further fragment analyte ions are of interest to increase the differentiating ability of this assay. ${ }^{39}$

The amplified sensitivity and specificity of LC-MS/MS have permitted quantifying free testosterone as low as $5 \mathrm{pmol} / \mathrm{L}$.

Drawbacks of MS: It requires high technical expertise. Therefore, not available in all laboratories due to the high cost of operation, lacking of standardization, special disposal is required for solvents used.

\section{Conclusion}

For men, testosterone levels are important to maintaining, but they naturally decrease over time. If symptoms of severe or chronic low testosterone are showing, hormone deficiency may be caused by an active disease or condition. Treatment can lead to unwanted side effects, so it is crucial to balance the expected benefits of testosterone with the risks of treatment.

In this review, we have tried to summarize how testosterone biosynthesis, regulation as well as metabolism occur in the body. How it plays numerous roles starting from intrauterine life to an advanced age, various factors such as age, weight, sleep, food habits, etc., affecting testosterone levels in the body. ${ }^{40}$ This is very important in understanding the clinical implications of testosterone on the health of an individual. At last, we have biochemically discussed various assays that are currently done for testosterone evaluation. Immunoassays are widely used to measure total testosterone levels but have limitations such as in specificity and precision mainly at low to very low levels of testosterone. Mass spectrometry when used in combination with chromatography has gradually been translated from a laboratory research technique to clinical application. It has increased specificity and accuracy of performance than immunoassays.

Still, there are several areas in the testosterone deficiency states, more specifically, epidemiology, diagnosis, treatment, and adverse events, which warrant more detailed investigation.

\section{Author's Statement}

The manuscript has been read and approved by all the authors, and each author believes that the manuscript represents honest work.

\section{References}

1. Basaria S. Reproductive aging in men. Endocrinol Metab Clin North Am 2013;42(2):255-270. DOI: 10.1016/j.ecl.2013.02.012.

2. Bassil N, Alkaade S, Morley JE. The benefits and risks of testosterone replacement therapy: a review. Ther Clin Risk Manag 2009;5(3):427448. DOI: 10.2147/tcrm.s3025.

3. Tuck SP, Francis RM. Testosterone, bone and osteoporosis. Front Horm Res 2009;37:123-132. DOI: 10.1159/000176049.

4. Luetjens CM, Weinbauer GF. Chapter 2: Testosterone: Biosynthesis, transport, metabolism and (non-genomic) actions. Cambridge: Cambridge University Press; 2012. pp. 15-32.

5. Van Helden J, Weiskirchen R. Cross-method comparison of serum androstenedione measurement with respect to the validation of a new fully automated chemiluminescence immunoassay. Clin Biochem 2018;62:32-38. DOI: 10.1016/j.clinbiochem.2018.09.009.

6. "Testosterone". Drugs.com. American Society of Health-System Pharmacists. 2015. Retrieved:2016. 
7. McEleny K. Testosterone: action, deficiency, substitution. BJU Int 2004;94(6):935. DOI: 10.1111/j.1464-410X.2004.5168_1.x.

8. Zitzmann M. Testosterone, mood, behaviour and quality of life. Andrology 2020;8(253). DOI: 10.1111/andr.12867.

9. Luetjens CM, Weinbauer GF. Testosterone: biosynthesis, transport, metabolism and (non-genomic) actions. Testosterone: action, deficiency, substitution Nieschlag E, Behre HM, ed., Cambridge: Cambridge University Press; 2012;2:15-33.

10. Al-Salem AH. Deficient testosterone biosynthesis. In: Pediatric gynecology. Cham: Springer; 2020. pp. 445-460.

11. Hackett G, Kirby M, Edwards D, et al. The British Society for Sexual Medicine guidelines on adult testosterone deficiency with statements for UK practice. J Sex Med 2017;14(12):1504-1523. DOI: 10.1016/j.jsxm.2017.10.067.

12. Allen NE, Key TJ, Dossus L, et al. Endogenous sex hormones and endometrial cancer risk in women in the European prospective investigation into cancer and nutrition (EPIC). Endocr Relat Cancer 2008;15(2):485-497. DOI: 10.1677/ERC-07-0064.

13. Sarkar NN. Hormonal profiles behind the heart of a man. Cardiol J 2009;16(4):300-306.

14. Calderon-Margalit R, Schwartz SM, Wellons MF, et al. Prospective association of serum androgens and sex hormone-binding globulin with subclinical cardiovascular disease in young adult women: the "Coronary Artery Risk Development in Young Adults" women's study. J Clin Endocrinol Metab 2010;95(9):4424-4431. DOI: 10.1210/jc.20092643.

15. Ahn HS, Park CM, Lee SW. The clinical relevance of sex hormone levels and sexual activity in the ageing male. BJU Int 2002;89(6):526-530. DOI: 10.1046/j.1464-410x.2002.02650.x.

16. Hoppé $E$, Bouvard $B$, Royer $M$, et al. Sex hormone-binding globulin in osteoporosis. Joint Bone Spine 2010;77(4):306-312. DOI: 10.1016/j. jbspin.2010.03.011.

17. Liverman CT, Blazer DG. Institute of Medicine (US) committee on assessing the need for clinical trials of testosterone replacement therapy. "Introduction". Testosterone and aging: clinical research directions. US: National Academies Press; 2004. p. 3.

18. Huhtaniemi I. Late-onset hypogonadism: current concepts and controversies of pathogenesis, diagnosis and treatment. Asian J Androl 2014;16(2):192-202. DOI: 10.4103/1008-682X.122336.

19. Huhtaniemi IT. Andropause--lessons from the European male ageing study. Ann Endocrinol 2014;75(2):128-131. DOI: 10.1016/j. ando.2014.03.005.

20. Håkonsen LB, Thulstrup AM, Aggerholm AS, et al. Does weight loss improve semen quality and reproductive hormones? Results from a cohort of severely obese men". Reprod Health 2011;8(1):24. DOI: 10.1186/1742-4755-8-24.

21. MacDonald AA, Herbison GP, Showell M, et al. The impact of body mass index on semen parameters and reproductive hormones in human males: a systematic review with meta-analysis. Hum Reprod Update 2010;16(3):293-311. DOI: 10.1093/humupd/dmp047.

22. Vingren JL, Kraemer WJ, Ratamess NA, et al. Testosterone physiology in resistance exercise and training: the up-stream regulatory elements. Sports Med 2010;40(12):1037-1053. DOI: 10.2165/11536910000000000-00000.

23. Hulmi JJ, Ahtiainen JP, Selänne $H$, et al. Androgen receptors and testosterone in men-effects of protein ingestion, resistance exercise and fiber type. J Steroid Biochem 2008;110(1-2):130-137. DOI: 10.1016/j.jsbmb.2008.03.030.

24. Hackney AC, Moore AW, Brownlee KK. Testosterone and endurance exercise: development of the "exercise-hypogonadal male condition". Acta Physiol Hung 2005;92(2):121-137. DOI: 10.1556/ APhysiol.92.2005.2.3.

25. Pilz S, Frisch S, Koertke $H$, et al. Effect of vitamin D supplementation on testosterone levels in men. Horm Metab Res 2011;43(3):223-225. DOI: 10.1055/s-0030-1269854.

26. Koehler K, Parr MK, Geyer H, et al. Serum testosterone and urinary excretion of steroid hormone metabolites after administration of a high-dose zinc supplement. Eur J Clin Nutr 2009;63(1):65-70. DOI: 10.1038/sj.ejcn.1602899.

27. Andersen ML, Tufik S. The effects of testosterone on sleep and sleep-disordered breathing in men: its bidirectional interaction with erectile function. Sleep Med Rev 2008;12(5):365-379. DOI: 10.1016/j. smrv.2007.12.003.

28. Akdoğan M, Tamer MN, Cüre E, et al. Effect of spearmint (Mentha spicata Labiatae) teas on androgen levels in women with hirsutism". Phytother Res 2007;21(5):444-447. DOI: 10.1002/ptr.2074.

29. Kumar V, Kural MR, Pereira BM, et al. Spearmint induced hypothalamic oxidative stress and testicular anti-androgenicity in male rats - altered levels of gene expression, enzymes and hormones. Food Chem Toxicol 2008;46(12):3563-3570. DOI: 10.1016/j.fct.2008.08.027.

30. Grant P. Spearmint herbal tea has significant anti-androgen effects in polycystic ovarian syndrome. A randomized controlled trial. Phytother Res 2010;24(2):186-188. DOI: 10.1002/ptr.2900.

31. Ramachandran S, Hackett GI, Strange RC. Sex hormone binding globulin: a review of its interactions with testosterone and age, and its impact on mortality in men with type 2 diabetes. Sex Med Rev 2019;7(4):669-678. DOI: 10.1016/j.sxmr.2019.06.006.

32. Vandenput $L$, Mellstrom $D$, Lorentzon $M$, et al. Androgens and glucuronidated androgen metabolites are associated with metabolic risk factors in men. J Clin Endocrinol Metab 2007;92(11):4130-4137. DOI: 10.1210/jc.2007-0252.

33. Nieschlag E, Behre HM, Nieschlag S. Testosterone: action, deficiency, substitution. Cambridge University Press; 2012. p. 61.

34. Fink HA, Ewing SK, Ensrud KE, et al. Association of testosterone and estradiol deficiency with osteoporosis and rapid bone loss in older men. J Clin Endocrinol Metab 2006;91(10):3908-3915. DOI: 10.1210/ jc.2006-0173.

35. Luetjens CM, Didolkar A, Kliesch S, et al. Tissue expression of the nuclear progesterone receptor in male non-human primates and men. J Endocrinol 2007;189(3):529-539. DOI: 10.1677/joe. 1.06348.

36. Modi DN, Shah C, Puri CP. Non-genomic membrane progesterone receptors on human spermatozoa. Soc Reprod Fertil Suppl 2007;63:515-529.

37. French $D$, Drees J, Stone JA, et al. Comparison of four clinically validated testosterone LC-MS/MS assays: Harmonization is an attainable goal. Clin Mass Spectrom 2019;11:12-20. DOI: 10.1016/j. clinms.2018.11.005.

38. Keevil BG, Adaway J. Assessment of free testosterone concentration. J Steroid Biochem 2019;190:207-211. DOI: 10.1016/j.jsbmb.2019. 04.008 .

39. Colletti JD, Redor-Goldman MM, Pomperada AE, et al. Sample multiplexing: increased throughput for quantification of total testosterone in serum by liquid chromatography-tandem mass spectrometry. Clin Chem 2020;66(9):1181-1189. DOI: 10.1093/ clinchem/hvaa117.

40. Maffei L, Murata $Y$, Rochira $V$, et al. Dysmetabolic syndrome in a man with a novel mutation of the aromatase gene: effects of testosterone, alendronate, and estradiol treatment. J Clin Endocrinol Metab 2004;89(1):61-70. DOI: 10.1210/jc.2003-030313. 